\title{
Sulitnya Regenerasi Petani pada Kelompok Generasi Muda
}

\author{
Irin Oktafiani', Marya Yenita Sitohang ${ }^{1}$, Rahmat Saleh ${ }^{1,2}$ \\ ${ }^{1}$ Researcher in Research Center for Population, Indonesian Institute of Sciences (LIPI), Indonesia \\ ${ }^{2}$ Master Program in Sociology, University of Indonesia, Indonesia \\ irin.oktafiani@gmail.com | maryayenita19@gmail.com | rahmat.saleh01@ui.ac.id
}

\begin{abstract}
Youth generation in the agrarian sector is needed to maintain food production and the possibility of discovering or developing new technologies. This article aims to describe the development of studies on farm children's existence, especially in Indonesia, and why many have decided not to become farmers. This article uses a qualitative research approach based on digital methods. Data were obtained through a literature review of 42 journal articles from previous research regarding children and young people in farming families. All data collected was processed using NVivo software. The findings of this study indicate that farmer regeneration in Indonesia faced various complex problems. Children's education factors, including dropping out of school, access to limited land, poverty, and migration activities, dominate the difficulty of regenerating farmers in farming families. This article also shows the need for intervention from various parties to support increased food security.
\end{abstract}

Keywords: Family Farming | Regeneration | Youth

Kontribusi: Dalam artikel ini, Irin Oktafiani, Marya Yenita Sitohang, dan Rahmat Saleh berperan sebagai Kontributor Utama.

\section{PENDAHULUAN}

Sektor pertanian sangat berkontribusi dalam penyerapan tenaga kerja di Indonesia. Setidaknya, satu dari tiga orang tenaga kerja di Indonesia berkecimpung dalam dunia pertanian (Kementerian Pertanian, 2015). Namun demikian, data Badan Pusat Statistik menunjukkan telah terjadi penurunan tingkat penyerapan tenaga kerja di sektor pertanian, yaitu dari sekitar $44,51 \%$ pada tahun 2004, menjadi 34,28\% di tahun 2014 (Pranadji dan Hardono, 2015). Fenomena penurunan tingkat penyerapan tenaga kerja di sektor pertanian ini terus terjadi hingga tahun 2018. Data Kementerian Pertanian menunjukkan bahwa terjadi penurunan jumlah tenaga kerja di sektor pertanian sebesar 1.080.722 jiwa dari tahun $2017 \mathrm{ke}$ tahun 2018 (Arvianti dkk., 2019). Penurunan tingkat penyerapan tenaga kerja di sektor pertanian menjadi hal yang cukup memprihatinkan mengingat ketahanan pangan nasional yang bertumpu pada sektor ini.

Upaya peningkatan penyerapan tenaga kerja di sektor pertanian merupakan hal yang kompleks. Tenaga kerja di sektor 
pertanian kerap menghadapi berbagai permasalahan yang mencakup rendahnya produktivitas, daya beli, tingkat kesejahteraan serta meningkatnya alih fungsi lahan dari sektor pertanian ke sektor non pertanian (Rusastra dan Suryadi, 2004; Nugroho et al., 2018). Hal ini menyebabkan terjadinya peralihan tenaga kerja dari sektor pertanian ke sektor non-pertanian (Nugroho et al., 2018). Begitu pula dengan golongan muda yang seharusnya menjadi roda penggerak dalam sektor pertanian. Sensus pertanian di tahun 2013 menunjukkan rendahnya proporsi petani berusia di bawah 35 tahun di Indonesia, yaitu sebesar 12,9\% (BPS, 2013). Penurunan angka penyerapan tenaga kerja di sektor pertanian dari tahun ke tahun menunjukkan bahwa belum banyak generasi muda yang masuk dalam sektor pertanian menggantikan kelompok tenaga kerja sebelumnya.

Permasalahan regenerasi petani ini juga dialami negara-negara lain yang bergerak di bidang agraria. Zapico, et al. (2019) dalam tulisannya memaparkan bahwa nilai terhadap kehidupan pertanian yang dianggap tidak 'bergengsi' juga berdampak terhadap aspirasi generasi muda di pedesaan, yang cenderung memilih bermigrasi ke kota untuk mencari pekerjaan yang dianggap lebih menjanjikan memberikan penghasilan, selain juga untuk tujuan pendidikan. Minimnya regenerasi petani dari kalangan muda menjadi stressor atau tekanan yang cukup 'mengguncang' dunia pertanian. Sejalan dengan kajian Zapico et al., Rodríguez et al. (2018) dalam tulisannya juga menyinggung tentang pudarnya nilai-nilai terkait tradisi lokal petani, hilang atau pudarnya minat generasi muda terhadap kegiatan pertanian, merupakan beberapa faktor sosial yang dapat mempengaruhi ketahanan sosial ekologi rumah tangga petani. Selain itu, karakteristik keluarga berupa jumlah anak, umur anak, dan ukuran keluarga mempengaruhi keputusan petani muda untuk beralih dari sektor pertanian ke sektor non-pertanian (Pranadji dan Hardono, 2015)

Proses regenerasi petani berkaitan juga dengan keluarga. Anak-anak muda yang terjun ke dunia pertanian umumnya terjadi melalui proses regenerasi petani dalam keluarga yang berarti pengelolaan usaha pertanian diwariskan dari orang tua kepada anaknya (Anwarudin dan Satria, 2020). Upaya pertanian keluarga ini telah terjadi sejak puluhan tahun yang lalu. Geertz (1963) melakukan kajian mengenai involusi pertanian di Jawa dan menemukan bahwa kehidupan keluarga petani Jawa berkaitan dengan budaya sekaligus terdesak oleh kehidupan ekonomi. Pandangan untuk memiliki banyak anak tidak diiringi dengan banyaknya lahan yang bisa diwariskan kepada anak-anak petani membawa dilema tersendiri dalam kehidupan mereka. Kuantitas tenaga kerja tidak didukung dengan luasnya lahan pertanian keluarga. Padahal, lahan yang diwariskan dari keluarga mendorong terjadinya proses regenerasi petani dan munculnya petanipetani muda.

Proses regenerasi petani yang terjadi dalam keluarga merupakan proses yang kompleks. Dalam beberapa tahun terakhir, terdapat beberapa penelitian yang berupaya untuk menggambarkan lebih dalam kompleksitas permasalahan regenerasi petani di Indonesia maupun secara global (Anwarudin, Satria, dan Fatchiya, 2018; Wardani dan Anwarudin, 2018; Anwarudin et al., 2019; Nazaruddin dan Anwarudin, 2019; Dayat, Anwarudin dan Makhmudi, 2020). Oleh karena itu, tulisan ini bertujuan untuk mendeskripsikan perkembangan studi-studi mengenai regenerasi petani secara nasional maupun global serta menganalisis faktor dibalik minimnya peran generasi muda dalam sektor pertanian.

\section{METODE PENELITIAN}

Artikel ini menggunakan pendekatan penelitian kualitatif, berbasis 
metode digital baik dalam pengumpulan data maupun pengolahan data. Penelitian ini menggunakan hasil penelitianpenelitian terdahulu sebagai sumber data. Pencarian artikel jurnal menggunakan search engine google secara umum, google scholar, dan situs pencarian jurnal internasional yaitu JSTOR, Elsevier, dan Wiley online library dengan kata kunci keluarga petani, petani muda, regenerasi keluarga petani, dan pertanian pemuda. Selanjutnya dalam bahasa inggris, kata kunci yang digunakan adalah family farmers, young farmers, farmers' regeneration. Penggunaan kata kunci ini bertujuan untuk membatasi topik penelitian secara umum dan sebagai pemetaan awal pada isu regenerasi petani. Setelah membaca judul dan abstrak dari penelitian- penelitian tersebut, kami memilih 42 literatur yang dianggap sesuai dengan tujuan dari studi ini yaitu berkaitan dengan regenerasi petani dan alasan dibalik keputusan anak dari keluarga petani. Dari 42 literatur tersebut, 20 penelitian berlokasi di Indonesia sedangkan 22 lainnya mengambil tempat di negara lain. Data literatur yang terpilih merupakan data terkait regenerasi petani di Indonesia yang dianalisis sejak 2014 hingga 2020, sedangkan tulisan terpilih dari negara lain merupakan hasil penelitian sejak tahun 1994 hingga 2020. Tidak ada konsekuensi signifikan dalam pemilihan tahun literatur karena perbedaan waktu tersebut tidak berdampak pada kasus-kasus regenerasi petani secara umum.

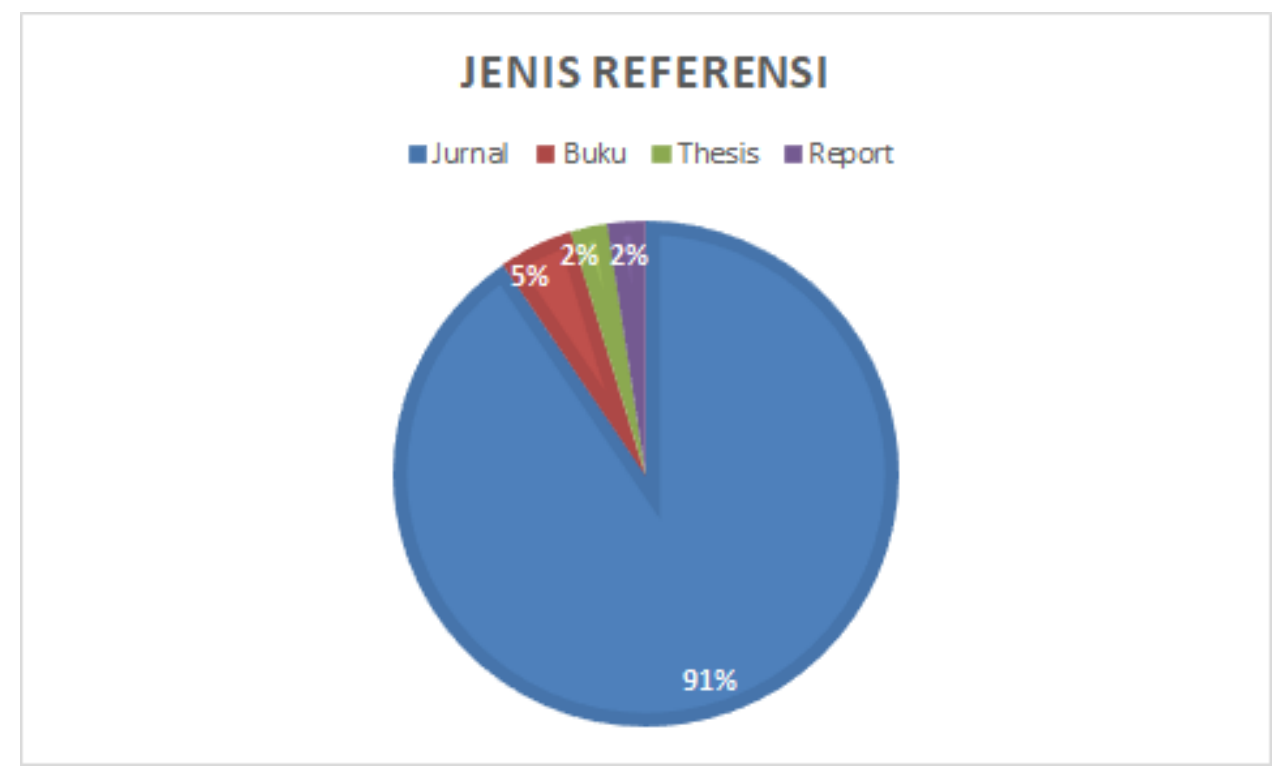

Sumber: Data Olahan Peneliti (2020)

Sebagian besar literatur yang didapatkan berbentuk artikel jurnal, diikuti dengan buku dan jenis naskah akademik lainnya berupa tesis dan laporan. Dominasi artikel jurnal yang digunakan dapat menggambarkan dengan lebih baik bagaimana dinamika fenomena dalam regenerasi petani muda. Kecepatan proses penulisan dan penerbitan naskah serta dinamisnya isu yang bisa diangkat dalam suatu jurnal menjadi beberapa faktor yang mendukung jurnal dalam menyajikan analisis terkait isu-isu aktual yang dalam hal ini terkait regenerasi petani. Setelah literatur terkumpul kemudian kami melakukan penelaahan dengan melihat konsep-konsep yang paling banyak muncul dari 42 literatur tersebut menggunakan software Nvivo untuk dibuat crosstab dan matriks. Melalui crosstab dan matriks, penulis kemudian dapat melihat dan menganalisis isu-isu yang paling sering muncul dalam keluarga petani dari 42 literatur tersebut. 
VISUALISASI OUTPUT LITERATUR REVIEW [SOFTWARE NVIVO]

Beberapa konsep kunci yang sering muncul dalam literatur-literatur terkait petani muda adalah akses, keterbatasan lahan, pendidikan, kemiskinan, petani muda, regenerasi, keluarga, resiliensi, putus sekolah, dan migrasi. Kata kunci ini menggambarkan isu-isu yang sering dibahas dalam menggambarkan petani muda atau regenerasi di dunia pertanian. Apabila dilihat dalam kurun waktu tertentu, perkembangan isu tersebut terlihat pada gambar 2 berikut.

Gambar 2. Perkembangan Studi Regenerasi Petani

Perkembangan Studi Regenerasi Petani

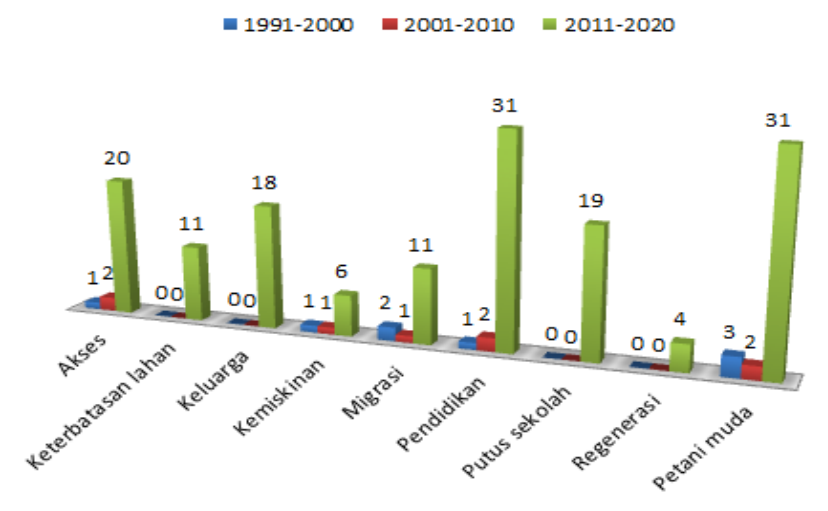

Sumber: Data Olahan Peneliti (2020)

Isu terkait akses (seperti akses terhadap lahan, pembiayaan, pasar, dan infrastruktur produksi -irigasi, pupuk, peralatan, jalan, transportasi-), kemiskinan, migrasi dan petani muda merupakan isu-isu awal yang sering muncul dalam kurun waktu 19992010. Sedangkan dalam sepuluh tahun terakhir, isu yang dibahas semakin berkembang yaitu membahas tentang keterbatasan lahan, keluarga, isu pendidikan yang lebih spesifik yaitu putus sekolah, regenerasi dan petani muda. Namun demikian, isu terkait kemiskinan, keterbatasan lahan dan migrasi cenderung kurang dibahas dalam literatur apabila dibandingkan dengan isu lain seperti akses, pendidikan dan putus sekolah. Dalam hal ini, petani muda menjadi subjek yang akan dibahas dan keluarga merupakan sistem dimana petani muda diharapkan bermunculan. 


\section{Gambar 3. Frekuensi Munculnya Kata Kunci}

Frekuensi Munculnya Kata Kunci
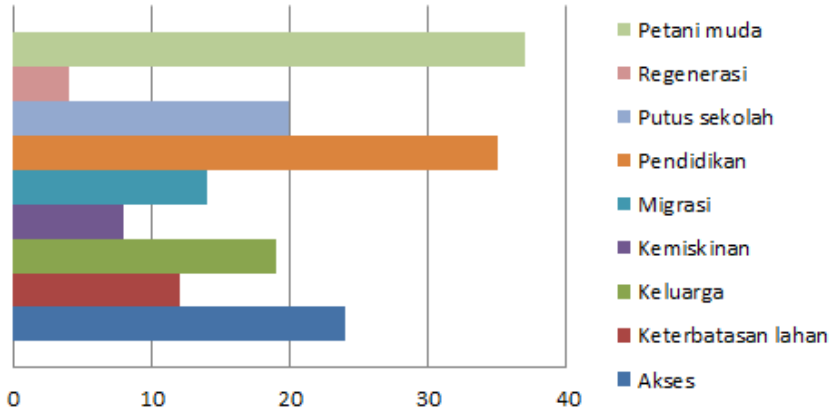

Sumber: Data Olahan Peneliti (2020

Dari sepuluh kata kunci tersebut kami mendapatkan hasil bahwa isu mengenai petani muda/young farmer paling banyak dibicarakan dari 42 literatur yang dikumpulkan. Petani muda dalam hal ini merupakan anak dari keluarga petani yang memutuskan untuk berkontribusi di sektor pertanian dan masih berusia muda. Sedangkan regenerasi merupakan kata kunci yang paling sedikit digunakan untuk menjelaskan fenomena petani muda dalam sektor pertanian. Hal ini dikarenakan regenerasi lebih sering dibahas secara implisit dalam sebuah penelitian sehingga mempengaruhi kemunculan kata kunci ini (sedikit muncul). Apabila dilihat lebih lanjut, pendidikan, putus sekolah dan akses menjadi isu yang sering dibahas para peneliti dalam menggambarkan petani muda. Studi Leavy dan Sally (2010) menyatakan bahwa pendidikan merupakan isu yang sering dibahas pada saat meneliti tentang petani muda.Tingkat kesejahteraan keluarga petani yang tergolong rendah membuat keluarga petani mengalami kesulitan dalam membiayai pendidikan anak-anaknya. Hal demikian membuat keluarga petani tidak mampu untuk melanjutkan pendidikan anak-anaknya (putus sekolah atau tidak lanjut ke jenjang yang lebih tinggi). Selain itu, keluarga petani menganggap bahwa menjadi petani kurang menjanjikan bagi masa depan anakanaknya, sehingga orangtua tidak mewariskannya. Keluarga petani mendorong anak-anaknya untuk bekerja di luar sektor pertanian. Oleh karena itu, hal ini menjadi salah satu penghambat dalam regenerasi petani.

Dari hasil olahan data ini, penulis akan menggambarkan lebih dalam fenomena petani muda dan alasan dibalik generasi muda atau anak dari keluarga petani memutuskan untuk menjadi petani sehingga terjadi regenerasi dalam sektor pertanian. Berikut pada tabel 1 di bawah ini adalah hasil crosstab literatur menurut kata kunci.

\section{Tabel 1. Crosstab Literatur}

\begin{tabular}{|c|l|l|} 
No. & \multicolumn{1}{|c|}{ Kata kunci } & \multicolumn{1}{c|}{ Penulis / Referensi } \\
\hline 1. & Akses & (Abrahams, 1992; Wolf, 2001; Brandth, 2002; Leavy and \\
& & $\begin{array}{l}\text { Sally, 2010; Price, 2012; Gutmann } \text { et al., 2012; Lehmann- } \\
\text { horn } \text { et al., 2014; Fischer and Burton, 2014; Kontogeorgos } \text { et } \\
\text { al., 2014; Moreno-Pérez and Lobley, 2015; Schewe, 2015; } \\
\text { Susilowati, 2016; The European Access to Land Network, }\end{array}$ \\
\hline
\end{tabular}




\begin{tabular}{|c|c|c|}
\hline & & $\begin{array}{l}\text { 2018; Carolan, 2018; Djurfeldt, 2018; Anwarudin et al., } \\
\text { 2019; May et al., 2019; Nazaruddin and Anwarudin, 2019; } \\
\text { Valliant et al., 2019, 2020; Korzenszky, 2019; Magagula and } \\
\text { Tsvakirai, 2020; Valliant and Freedgood, 2020; Dayat, } \\
\text { Anwarudin and Makhmudi, 2020) }\end{array}$ \\
\hline 2. & Keterbatasan Lahan & $\begin{array}{l}\text { (Susilowati, 2016; Suryati and Yuniati, 2017; Pamungkaslara, } \\
\text { 2017; Arimbawa and Rustariyuni, 2018; Laa, 2018; Pranata, } \\
\text { 2018; Arvianti et al., 2019; Kusumo and Mukti, 2019; } \\
\text { Anwarudin and Satria, 2020; Santoso, Effendy and } \\
\text { Krisnawati, 2020) }\end{array}$ \\
\hline 3. & Keluarga & $\begin{array}{l}\text { (Rahayu, 2014; Anshar and Syukur, 2016; Musrah, 2016; } \\
\text { Susilowati, 2016; Pamungkaslara, 2017; Suryati and Yuniati, } \\
\text { 2017; Mua, Manginsela and Baroleh, 2017; Pranata, 2018; } \\
\text { Wardani and Anwarudin, 2018; Wehantouw, Manginsela and } \\
\text { Moniaga, 2018; Arimbawa and Rustariyuni, 2018; Laa, 2018; } \\
\text { Nazaruddin and Anwarudin, 2019; Anwarudin et al., 2019; } \\
\text { Arvianti et al., 2019; Kusumo and Mukti, 2019; Anpersya } \\
\text { and Wirdanengsih, 2020; Anwarudin and Satria, 2020; Dayat, } \\
\text { Anwarudin and Makhmudi, 2020) }\end{array}$ \\
\hline 4. & Resiliensi & $\begin{array}{l}\text { (Abrahams, 1992; Djurfeldt, 1996, 2018; Wolf, 2001; Fischer } \\
\text { and Burton, 2014; Lehmann-horn et al., 2014; Carolan, 2018; } \\
\text { The European Access to Land Network, 2018; Anwarudin } \text { et } \\
\text { al., 2019; Nazaruddin and Anwarudin, 2019; Anwarudin and } \\
\text { Satria, 2020) }\end{array}$ \\
\hline 5. & Kemiskinan & $\begin{array}{l}\text { (Abrahams, 1992; Wolf, 2001; Leavy and Sally, 2010; Price, } \\
\text { 2012; Djurfeldt, 2018; The European Access to Land } \\
\text { Network, 2018; Magagula and Tsvakirai, 2020) }\end{array}$ \\
\hline 6. & Migrasi & $\begin{array}{l}\text { (Abrahams, 1992; Moxnes Jervell, 1999; Wolf, 2001; Leavy } \\
\text { and Sally, 2010; Price, 2012; Gutmann et al., 2012; } \\
\text { Susilowati, 2016; Mua, Manginsela and Baroleh, 2017; The } \\
\text { European Access to Land Network, 2018; Carolan, 2018; } \\
\text { Arvianti et al., 2019; Korzenszky, 2019; May et al., 2019; } \\
\text { Magagula and Tsvakirai, 2020) }\end{array}$ \\
\hline 7. & Pendidikan & $\begin{array}{l}\text { (Moxnes Jervell, 1999; Wolf, 2001; Brandth, 2002; Leavy } \\
\text { and Sally, 2010; Lehmann-horn et al., 2014; Rahayu, 2014; } \\
\text { Fischer and Burton, 2014; Kontogeorgos et al., 2014; } \\
\text { Moreno-Pérez and Lobley, 2015; Schewe, 2015; Anshar and } \\
\text { Syukur, 2016; Musrah, 2016; Susilowati, 2016; Mua, } \\
\text { Manginsela and Baroleh, 2017; Pamungkaslara, 2017; Suryati } \\
\text { and Yuniati, 2017; Laa, 2018; Pranata, 2018; The European } \\
\text { Access to Land Network, 2018; Arimbawa and Rustariyuni, } \\
\text { 2018; Wardani and Anwarudin, 2018; Wehantouw, }\end{array}$ \\
\hline
\end{tabular}




\begin{tabular}{|c|c|c|}
\hline & & $\begin{array}{l}\text { Manginsela and Moniaga, 2018; Carolan, 2018; Korzenszky, } \\
\text { 2019; Kusumo and Mukti, 2019; May et al., 2019; } \\
\text { Anwarudin et al., 2019; Nazaruddin and Anwarudin, 2019; } \\
\text { Valliant et al., 2019, 2020; Arvianti et al., 2019; Anpersya } \\
\text { and Wirdanengsih, 2020; Magagula and Tsvakirai, 2020; } \\
\text { Santoso, Effendy and Krisnawati, 2020; Dayat, Anwarudin } \\
\text { and Makhmudi, 2020) }\end{array}$ \\
\hline 8. & Putus Sekolah & $\begin{array}{l}\text { (Rahayu, 2014; Moreno-Pérez and Lobley, 2015; Anshar and } \\
\text { Syukur, 2016; Musrah, 2016; Susilowati, 2016; Mua, } \\
\text { Manginsela and Baroleh, 2017; Suryati and Yuniati, 2017; } \\
\text { Pranata, 2018; The European Access to Land Network, 2018; } \\
\text { Wardani and Anwarudin, 2018; Wehantouw, Manginsela and } \\
\text { Moniaga, 2018; Arimbawa and Rustariyuni, 2018; Carolan, } \\
\text { 2018; Laa, 2018; Nazaruddin and Anwarudin, 2019; Arvianti } \\
\text { et al., 2019; Kusumo and Mukti, 2019; Anpersya and } \\
\text { Wirdanengsih, 2020; Anwarudin and Satria, 2020; Magagula } \\
\text { and Tsvakirai, 2020) }\end{array}$ \\
\hline 9. & Regenerasi & $\begin{array}{l}\text { (Rahayu, 2014; Anshar and Syukur, 2016; Musrah, 2016; } \\
\text { Mua, Manginsela and Baroleh, 2017) }\end{array}$ \\
\hline 10. & Petani Muda & $\begin{array}{l}\text { (Abrahams, 1992; Moxnes Jervell, 1999; Wolf, 2001; } \\
\text { Brandth, 2002; Leavy and Sally, 2010; Gutmann et al., 2012; } \\
\text { Price, 2012; Fischer and Burton, 2014; Kontogeorgos et al., } \\
\text { 2014; Lehmann-horn et al., 2014; Moreno-Pérez and Lobley, } \\
\text { 2015; Schewe, 2015; Susilowati, 2016; Pamungkaslara, 2017; } \\
\text { Laa, 2018; Pranata, 2018; The European Access to Land } \\
\text { Network, 2018; Wardani and Anwarudin, 2018; Wehantouw, } \\
\text { Manginsela and Moniaga, 2018; Arimbawa and Rustariyuni, } \\
\text { 2018; Carolan, 2018; Djurfeldt, 2018; Korzenszky, 2019; } \\
\text { Kusumo and Mukti, 2019; May et al., 2019; Nazaruddin and } \\
\text { Anwarudin, 2019; Anwarudin et al., 2019; Valliant et al., } \\
\text { 2019, 2020; Arvianti et al., 2019; Anpersya and } \\
\text { Wirdanengsih, 2020; Magagula and Tsvakirai, 2020; } \\
\text { Anwarudin and Satria, 2020; Santoso, Effendy and } \\
\text { Krisnawati, 2020; Valliant and Freedgood, 2020; Dayat, } \\
\text { Anwarudin and Makhmudi, 2020) }\end{array}$ \\
\hline
\end{tabular}

Sumber: Data Olahan Peneliti (2020)

KRISIS PADA SEKTOR PERTANIAN: KONDISI DEMOGRAFI DAN LUAS LAHAN

Populasi penduduk terus bertambah, walaupun dengan kecepatan yang menurun. Jumlah penduduk saat ini mendekati 7,5 miliar orang, yang berarti terjadi peningkatan lebih dari 100 persen sejak tahun 1960-an. Beberapa wilayah mengalami fenomena yang disebut transisi demografi, dimana terjadi peningkatan angka harapan hidup yang sekaligus dibarengi dengan penurunan angka 
fertilitas secara perlahan. Walaupun demikian, fenomena ini tidak terjadi di seluruh wilayah. Di beberapa wilayah seperti di Asia Selatan dan Sub-Sahara Afrika misalnya, populasi penduduk muda memiliki tingkat fertilitas yang tinggi, yang mengakibatkan angka pertumbuhan penduduk yang tinggi. Pergerakan penduduk dari area rural ke urban sepertinya masih terus berlanjut. Saat ini hanya $45 \%$ dari total penduduk dunia yang masih terklasifikasi rural, berdasarkan definisi rural di masing-masing negara (FAO, 2019).

Berkaitan dengan hal tersebut di atas, yang mana penduduk membutuhkan makan setiap hari maka sektor pangan dan pertanian harus terus dijaga. Karena sektor ini menghasilkan bahan pangan yang dikonsumsi setiap hari oleh seluruh umat manusia di dunia. Namun faktanya, data pada tabel 2 di bawah ini menunjukkan kondisi sebaliknya. Pada tahun 2017, sektor pertanian hanya menggunakan $37 \%$ dari luas daratan global. Secara regional, proporsi ini merupakan lebih dari 50\% dari total tanah di Asia, dan kurang dari 25\% di Eropa. Secara keseluruhan, baik global maupun regional di Asia, trennya adalah terjadi penurunan minat untuk menjadi pekerja di sektor pertanian (petani, persoalan regenerasi) meskipun luas lahan pertanian cenderung stabil dari tahun 19972017.

Tabel 2. Tenaga Kerja dan Lahan pada Sektor Pertanian

\begin{tabular}{|l|c|c|c|}
\hline WORLD & $\mathbf{1 9 9 7}$ & $\mathbf{2 0 0 7}$ & $\mathbf{2 0 1 7}$ \\
\hline Employment in agriculture (\%) & 40.3 & 35.0 & 28.5 \\
\hline Agricultural land area (\% of total land area) & 37.6 & 37.3 & 37.1 \\
\hline
\end{tabular}

\begin{tabular}{|l|c|c|c|}
\hline \multicolumn{1}{|c|}{ ASIA } & $\mathbf{1 9 9 7}$ & $\mathbf{2 0 0 7}$ & $\mathbf{2 0 1 7}$ \\
\hline Employment in agriculture (\%) & 49.0 & 41.8 & 31.9 \\
\hline Agricultural land area (\% of total land area) & 53.4 & 52.9 & 53.6 \\
\hline
\end{tabular}

\section{Sumber: FAO (2019), diolah oleh peneliti}

Lebih rinci di tingkat global, sekitar 1,5 miliar petani hidup dari lahan kecil kurang dari 2 hektar, 410 juta orang mengumpulkan hasil hutan dan padang rumput, 100-200 juta orang menjadi penggembala ternak, 100 juta orang berprofesi sebagai nelayan kecil, serta 370 juta lainnya merupakan kelompok masyarakat adat yang sebagian besar bertani (FAO 2017).
Kondisi sektor pertanian di tingkat Asia Tenggara, meskipun lahan pertanian cenderung mengalami perluasan tetapi terjadi tren penurunan pada minat pekerjanya (petani, persoalan regenerasi). Data pada tabel 3 di bawah ini menunjukkan kondisi demikian. Jumlah masyarakat yang bekerja sebagai petani cenderung terus mengalami penurunan. Ditambah lagi masyarakat yang hidup di desa pindah ke kota karena pekerjaan 
sebagai petani dirasa kurang menjanjikan. Penurunan pekerja sektor pertanian ini tentu mempengaruhi produksi pangan. Sementara jumlah masyarakat di perkotaan yang bukan bekerja di sektor pertanian, terus bertambah. Selain itu, penduduk perkotaan juga cenderung mengkonsumsi makanan yang lebih beragam dibanding penduduk desa. Artinya, penduduk desa yang sebagai petani, harus memberi makan penduduk di seluruh negeri, jumlah pangan yang diproduksi juga harus lebih banyak ragamnya.

Tabel 3. Tenaga Kerja dan Lahan pada Sektor Pertanian

\begin{tabular}{|c|c|c|c|}
\hline ASEAN & 1997 & 2007 & 2017 \\
\hline \multicolumn{4}{|l|}{ Employment in agriculture (\%) } \\
\hline - Brunei Darussalam & 1.4 & 0.8 & 1.4 \\
\hline - Kamboja & 75.0 & 50.9 & 30.8 \\
\hline - Indonesia & 41.2 & 41.3 & 30.8 \\
\hline - Laos & 83.2 & 75.2 & 68.4 \\
\hline - Malaysia & 17.3 & 14.8 & 11.2 \\
\hline - Myanmar & 63.3 & 56.0 & 50.6 \\
\hline - Filipina & 40.4 & 34.5 & 25.4 \\
\hline - Singapore & 1.0 & 1.0 & 0.5 \\
\hline - Thailand & 50.4 & 39.5 & 30.9 \\
\hline - Vietnam & - & - & - \\
\hline
\end{tabular}

\begin{tabular}{|c|c|c|c|}
\hline ASEAN & 1997 & 2007 & 2017 \\
\hline \multicolumn{4}{|c|}{ Agricultural land area ( $\%$ of total land area) } \\
\hline - Brunei Darussalam & 1.9 & 2.2 & 2.7 \\
\hline
\end{tabular}




\begin{tabular}{|l|c|c|c|}
\hline - Kamboja & 25.9 & 30.3 & 31.5 \\
\hline - Indonesia & 24.0 & 29.3 & 33.2 \\
\hline - Laos & 7.6 & 8.9 & 10.4 \\
\hline - Malaysia & 21.2 & 21.6 & 26.1 \\
\hline - Myanmar & 16.1 & 18.3 & 19.7 \\
\hline - Filipina & 38.0 & 39.5 & 41.7 \\
\hline - Singapore & 1.8 & 1.2 & 0.9 \\
\hline - Thailand & 40.0 & 38.8 & 43.3 \\
\hline - Vietnam & - & - & - \\
\hline
\end{tabular}

Sumber: FAO (2019), diolah oleh peneliti

Terkait persoalan regenerasi, golongan muda merupakan masalah sendiri. Saat ini dengan populasi lebih kurang seperlima populasi dunia, namun mereka enggan berkarir di sektor pertanian. Ide yang berkembang untuk menarik mereka ke dalam pertanian, selain berusaha mendorongnya menjadi petani secara langsung, juga ditawarkan untuk profesi lain yang tidak langsung, yakni pengusaha pangan (food entrepreneurs), ilmuwan, dan penyuluh pertanian (extension agents). Namun, untuk mendapatkan hasil yang lebih signifikan, maka pemerintah perlu membantu petani muda untuk akses kepada lahan, kredit perbankan, pendidikan, serta keterampilan teknis yang memadai (FAO 2014).

\section{PERMASALAHAN REGENERASI PETANI DI INDONESIA}

Stereotip dan Sulitnya Regenerasi Petani

Pada konteks ini dapat dikatakan bahwa sulitnya regenerasi petani erat kaitannya dengan stereotip yang ada di masyarakat. Setidaknya terdapat dua stereotip kuat mengenai petani, yang pertama adalah pertanian erat dengan eksistensi laki-laki. Bagi Brandth (2002, p. 184), pertanian keluarga adalah patriarki karena laki-laki dekat dengan kepemilikan lahan, sedangkan perempuan hanya bisa berkontribusi sejauh pengorganisasian lahan dan strategi penjualan hasil produksi. Pewarisan lahan umum diberikan kepada anak laki-laki sedangkan perempuan hanya bisa menjadi istri dari pemilik lahan. Dalam laporannya Li (2015:3-14) pada pertanian kelapa sawit di Kalimantan Barat dijelaskan posisi perempuan sebagai istri pemilik lahan pun tetap tereksklusi. Ia menemukan bahwa perempuan tidak memiliki hak untuk ikut menentukan pada saat suami memilih untuk menggadaikan lahan atau menjualnya. Padahal, dalam proses produksi perempuan memiliki beban kerja yang sama. Sayangnya, tetap saja kerja pertanian dianggap sebagai kerja laki-laki. Oleh karena itu anak-anak perempuan jarang yang mau melanjutkan pekerjaan sebagai petani karena pekerjaan ini dianggap berada di domain laki-laki. 
Stereotipe kedua yaitu petani adalah profesi yang dekat dengan kemiskinan. Bertani dianggap menjadi pekerjaan yang jauh dari kemapanan dan kesejahteraan karena sering dikaitkan dengan kondisi kehidupan masyarakat desa (Leavy and Sally, 2010:7-10). Menjadi petani dianggap tidak menguntungkan karena kadang kala ongkos produksi melampaui harga jual dari hasil tanam. Bayang-bayang kemiskinan menghantui para generasi muda, baik yang berasal dari keluarga petani maupun bukan. Ditambah lagi karena pertanian erat dengan bisnis keluarga, maka para (calon) petani muda ini hanya bisa bergantung kepada peran keluarga/kerabat dibandingkan kepada pemerintah.

Terkait dengan regenerasi petani, Arimbawa dan Rustariyuni (Arimbawa and Rustariyuni, 2018:1565) menjelaskan bahwa tingkat pendidikan tinggi berbanding terbalik dengan keputusan anak muda untuk meneruskan menjadi petani. Hal ini ternyata didukung oleh keinginan dari orangtua agar anak mereka tidak menjadi petani lagi. Wehantouw, Manginsela dan Moniaga, (2018:9), dalam penelitian di Desa Treman, Minahasa Utara, menyatakan bahwa alasan generasi muda bekerja di sektor non-pertanian adalah ingin memiliki status ekonomi yang lebih tinggi daripada menjadi petani, seperti memiliki pendapatan tetap. Dari kedua tulisan dapat terlihat bahwa keengganan untuk menjadi petani muncul tidak hanya dari dalam diri sendiri akan tetapi juga dibentuk oleh lingkungan. Generasi muda merasa bahwa menjadi petani bukanlah keputusan yang baik karena tidak bisa menaikkan status sosial mereka ditambah lagi, tingkat pendidikan yang tinggi dianggap tidak sepadan dengan profesi ini.

Kedua stereotip tersebut di atas dapat terbentuk dan langgeng di masyarakat tidak terlepas dari adanya transmisi nilai atau yang dikenal sebagai sosialisasi. Peranan ini dipegang oleh keluarga sebagai unit sosial terkecil yang memiliki fungsi sosialisasi kepada anak (Georgas dkk.,
2001). Melalui transmisi nilai dalam keluarga, anak belajar untuk menilai apa yang dianggap lebih baik untuk dilakukan. Ditambah lagi dengan peranan lingkungan sosial yang dapat memberikan konteks nilai, norma, budaya lokal di dalam suatu masyarakat. Nilai-nilai yang ditransmisikan, baik yang dilakukan oleh keluarga maupun lingkungan sosial, kemudian mempengaruhi perkembangan personal anak atau individu dalam kesiapannya untuk 'terjun' di masyarakat. Peran keluarga dan lingkungan kemudian melegitimasi bagaimana stereotip kehidupan petani yang sulit sejahtera menjadi hal yang lumrah terjadi dalam masyarakat. Sehingga berprofesi sebagai petani merupakan opsi terakhir untuk dipilih bahkan di dalam keluarga petani itu sendiri.

Sementara itu di tengah sulitnya regenerasi petani mulai bermunculan gerakan-gerakan pendukung bagi anak petani dan generasi muda petani. Setidaknya di Eropa dan Amerika Utara gerakan dukungan kepada young farmers mulai bergairah kembali. Dukungandukungan dilakukan mulai dari edukasi petani pemula dan dukungan pinjaman serta sistem pengelolaan tanah yang dipermudah (Gutmann et al., 2012; Price, 2012; Fischer and Burton, 2014; Carolan, 2018; The European Access to Land Network, 2018; Korzenszky, 2019; May et al., 2019; Valliant et al., 2019; Valliant and Freedgood, 2020). Di Indonesia, percepatan regenerasi petani dilakukan diantaranya dengan memperbanyak dukungan baik dari segi edukasi, diantaranya perbaikan persepsi orangtua mengenai status ekonomi petani, penyuluhan terkait produksi dan distribusi hasil pertanian, hingga dukungan ekonomi berupa bantuan-bantuan dari pemerintah (Anwarudin, Satria and Fatchiya, 2018; Wardani and Anwarudin, 2018; Anwarudin et al., 2019; Anwarudin and Satria, 2020; Dayat, Anwarudin and Makhmudi, 2020). Dari beberapa studi terkait percepatan regenerasi tersebut, 
penulis melihat bahwa dukungan masyarakat non-petani juga tidak kalah penting untuk membantu regenerasi petani. Hal ini terkait dengan usaha-usaha menaikkan kesejahteraan petani sehingga akan banyak orang yang bisa tertarik untuk mengembangkan sektor pertanian. Oleh karena itu dukungan semua pihak sebagai faktor eksternal penting untuk mendukung percepatan regenerasi petani.

\section{Dilema Pendidikan Tinggi Petani Muda}

Keluarga petani merupakan sistem yang menjalankan berbagai fungsi keluarga, seperti fungsi ekonomi dan pengasuhan pada anak (Laa, 2018). Fungsifungsi yang dijalankan petani sebagai orang tua akan berdampak pada proses pendidikan anak-anak dalam keluarga tersebut (Rahayu, 2014; Musrah, 2016; Mua, Manginsela and Baroleh, 2017; Anpersya and Wirdanengsih, 2020). Meskipun ada yang mengungkapkan bahwa tingkat pendidikan petani tersebut tidak berpengaruh pada tingkat pendidikan anakanaknya (Dayat, Anwarudin and Makhmudi, 2020), tetapi menurut Santoso, dkk ( 2020) tingkat pendidikan, baik formal maupun informal, berpengaruh nyata terhadap percepatan regenerasi petani. Menurut penelitian yang dilakukan Nazaruddin dan Anwarudin (2019), terjadi peningkatan pendidikan di kalangan petani yang dulunya didominasi oleh Sekolah Dasar saat ini menjadi Sekolah Menengah Pertama. Namun, bila dibedakan antara petani di desa dan di kota, petani desa memiliki tingkat pendidikan yang lebih rendah daripada petani kota (Pamungkaslara, 2017).

Pola pengasuhan petani yang berkaitan dengan pendidikan anaknya cukup beragam. Beberapa petani bersifat netral dan membebaskan pilihan menempuh pendidikan pada anaknya. Namun, ada petani yang merasa pendidikan tidak terlalu penting karena hanya berujung pada mencari kerja yang sebenarnya bisa langsung dilakukan di sektor pertanian tanpa menempuh proses pendidikan tinggi (Musrah, 2016). Intervensi dari orang tua tersebut, ditambah dengan kondisi ekonomi yang kurang memadai sering menjadi alasan dibalik kejadian putus sekolah di antara anak-anak petani (Anshar and Syukur, 2016; Mua, Manginsela and Baroleh, 2017). Dalam suatu penelitian di suatu desa, fenomena putus sekolah anak yang berasal dari keluarga petani ditemukan mencapai 70\% (Pranata, 2018). Selain itu, dalam keluarga petani, anakanak memang sering dimanfaatkan sebagai sumber daya untuk bekerja dalam sektor pertanian dengan alibi memberi kesempatan pada mereka untuk mengembangkan potensi diri (Suryati and Yuniati, 2017).

Di lain pihak, terdapat petani yang menganggap pendidikan setinggi-tingginya sebagai upaya meningkatkan taraf hidup (Musrah, 2016). Petani yang mendukung pendidikan anaknya akan memberikan bimbingan, keteladanan tidak hanya dalam pendidikan intelektual tetapi juga psikis dan sosial, serta memberi motivasi pada anaknya agar lebih giat belajar (Rahayu, 2014). Tidak heran terdapat sebagian kecil petani muda yang memiliki gelar sarjana (Kusumo and Mukti, 2019). Meski ada kemungkinan jurusan yang diambil para petani muda tidak terkait dengan sektor pertanian (The European Access to Land Network, 2018).

Generasi muda sebagai sumber daya manusia di bidang pertanian memang memerlukan perbaikan dan peningkatan pendidikan dan keterampilan agar sesuai dengan kebutuhan dan mampu melakukan inovasi yang meningkatkan produktivitas pertanian (Susilowati, 2016; Anwarudin et al., 2019; Kusumo and Mukti, 2019; Anwarudin and Satria, 2020). Pendidikan di bidang pertanian dan aplikasi pada usaha tani oleh petani muda menjadi contoh suksesnya regenerasi petani meski orang tua tidak memberikan pengetahuan dan pengalaman di bidang pertanian (Korzenszky, 2019). Salah satu penelitian 
menunjukkan gagalnya regenerasi petani di daerah perdesaan karena kurangnya pengetahuan dan pendidikan tentang pertanian (Dayat, Anwarudin and Makhmudi, 2020). Pendidikan yang terkait dengan sektor pertanian juga perlu didukung secara ekonomi agar generasi muda dapat terjun ke sektor pertanian (Magagula and Tsvakirai, 2020).

Peralihan dari sektor pertanian ke sektor non-pertanian sering terjadi karena generasi muda memilih pekerjaan yang sesuai dengan bidang pendidikan tinggi yang diambil (Susilowati, 2016; Wehantouw, Manginsela and Moniaga, 2018). Menumbuhkan minat dan keterampilan generasi muda pada bidang pertanian telah dilakukan sejak zaman penjajahan Belanda melalui Sekolah Pertanian Rendah, Sekolah Tani Rakyat dan banyak upaya pemerintah lainnya yang dilakukan hingga saat ini baik dalam bentuk pendidikan formal maupun informal (Anwarudin, Satria and Fatchiya, 2018; Arvianti et al., 2019; Anwarudin and Satria, 2020). Selain itu, upaya menumbuhkan minat dan ketertarikan generasi muda ke sektor pertanian dapat dilakukan sejak pendidikan dasar dan melalui peran orang tua yang mendukung anaknya untuk berkontribusi di sektor pertanian meskipun berpendidikan tinggi (Susilowati, 2016; Arimbawa and Rustariyuni, 2018).

\section{KESIMPULAN}

Sulitnya regenerasi petani muda merupakan sebuah fenomena global. Secara keseluruhan, baik global maupun regional di Asia terjadi penurunan minat untuk menjadi pekerja di sektor pertanian meskipun luas lahan pertanian cenderung stabil. Temuan penelitian ini menunjukan bahwa dalam dua dekade terakhir isu yang terkait regenerasi petani muda antara lain akses (termasuk keterbatasan lahan), kemiskinan, keluarga, dan pendidikan. Akan tetapi term regenerasi ini sendiri paling sedikit digunakan untuk menjelaskan fenomena petani muda dalam sektor pertanian.

Tulisan ini juga menunjukkan bahwa fenomena sulitnya regenerasi petani muda bukan semata-mata terkait dengan keengganan anak-anak petani melainkan juga dibentuk oleh nilai-nilai yang berlaku pada keluarga dan masyarakat pertanian. Beberapa nilai tersebut diantaranya adalah stereotip bahwa dunia pertanian dekat dengan dunia laki-laki, kemiskinan, rendahnya tingkat pendidikan, dan tingginya tingkat putus sekolah dalam keluarga petani. Keluarga memiliki peranan penting dalam proses regenerasi petani karena fungsinya dalam mentransmisikan nilai dan fungsi ekonomi yang berkaitan dengan pendidikan anak (termasuk pembiayaan). Tingkat pendidikan anak petani berperan penting dalam meningkatkan kesejahteraan keluarga petani. Akan tetapi di dalam keluarga petani terdapat anggapan bahwa untuk terjun ke sektor pertanian tidak memerlukan pendidikan yang mumpuni. Seharusnya keluarga petani perlu meyakinkan anaknya bahwa pendidikan tinggi dibutuhkan agar petani muda mampu melakukan inovasi. Selain itu, masyarakat berperan penting dalam membangun optimisme terhadap masa depan dunia pertanian apabila anakanak mereka tertarik untuk berkontribusi di sektor tersebut. Pada konteks ini, keputusan untuk tidak menjadi petani juga terkait dengan transmisi nilai dari orangtua yang tidak menginginkan anaknya untuk meneruskan profesi tersebut.

Di sisi yang lain, keberhasilan regenerasi petani muda bisa didapatkan apabila adanya dukungan keuangan serta pendidikan tinggi sehingga anak dari keluarga petani mau melanjutkan profesi ini dan mampu melakukan inovasi-inovasi di dunia pertanian. Beberapa pihak baik pemerintah maupun komunitas telah melakukan upaya dukungan berupa edukasi dan pemberian sumberdaya seperti lahan dan pinjaman modal untuk mendukung kontribusi generasi muda dalam sektor 
pertanian. Hal ini tentunya menjadi angin segar bagi sektor pertanian dan studi agraria secara umum. Oleh karena itu, apabila upaya dukungan terhadap petani muda semakin meluas, regenerasi petani akan bisa dilakukan secara optimal dan menjadi sebuah gerakan yang berkelanjutan dalam masyarakat. Terakhir, penulis menyaranlan untuk penelitian selanjutnya agar dilakukan secara empiris dan lebih mendalam terkait upaya-upaya regenerasi petani yang dilakukan di tingkat keluarga petani dan pemangku kebijakan di Indonesia. 


\section{DAFTAR PUSTAKA}

Anpersya, F. O. \& Wirdanengsi, W. 2020. Penanaman Nilai-Nilai Pendidikan Dalam Keluarga Petani yang Memiliki Anak Putus Sekolah Tingkat SLTP di Jorong IV Rotan Getah. Jurnal Perspektif: Jurnal Kajian Sosiologi dan Pendidikan, 3(3), pp. 528-534.

Anshar, H. \& Syukur, M. 2018. Strategi Keluarga Petani Dalam Melanjutkan Pendidikan Anak Ke Perguruan Tinggi I Desa Pebaloran Kecamatan Curio Kabupaten Enrekang. Jurnal Sosialisasi Pendidikan Sosiologi-FIS UNM, pp. 57-62.

Anwarudin, O. et al. 2019. Factors influencing the entrepreneurial capacity of young farmers for farmer succession. International Journal of Innovative Technology and Exploring Engineering, 9(1), pp. 1008-1014. doi: 10.35940/ijitee.A4611.119119.

Anwarudin, O. \& Satria, A. 2020. Proses dan Pendekatan Regenerasi Petani Melalui Multistrategi di Indonesia. Jurnal Litbang Pertanian, 39(2), pp. 73-85. doi: 10.21082/jp3.v39n2.2020.p73-85.

Anwarudin, O., Satria, A., \& Fatchiya, A. 2018. A Review on Farmer Regeneration and Its Determining Factors in Indonesia. International Journal of Progressive Sciences and Technologies, 10(2), pp. 218230.

Arimbawa, I. P. E. \& Rustariyuni, S. D. 2018. Respon Anak Petani Meneruskan Usaha Tani Keluarga di Kecamatan Abiansemal. Ejurnal EP Unud, 7(7), pp. 15581586.

Arvianti, E. Y., Masyhuri, M., Waluyati, L. R., \& Darwanto, D. H. 2019.
Gambaran Krisis Petani Muda Indonesia. Agriekonomika, 8(2), 168-180.

https://doi.org/10.21107/agriekono mika.v8i2.5429

Badan Pusat Statistik (BPS). 2013. Hasil Sensus Pertanian. Jakarta: BPS.

Brandth, B. 2002. Gender identity in European family farming: A literature review. Sociologia Ruralis, 42(3), 181-200. https://doi.org/10.1111/1467$\underline{9523.00210}$

Dayat, D., Anwarudin, O., \& Makhmudi, M. 2020. Regeneration of farmers through rural youth participation in chili agribusiness. International Journal of Scientific and Technology Research, 9(3), pp. 1201-1206.

Food and Agriculture Organization. 2020. FAO Statistical Yearbooks - World food and agriculture 2019. Rome: Food and Agriculture

Organization. http://www.fao.org/economic/ess/e ss-publications/essyearbook/en/\#.X3Hrs2gzbIU

Food and Agriculture Organization. 2020. Selected Indicators. Rome: Food and Agriculture

Organization.http://www.fao.org/fa ostat/en/\#country

Food and Agriculture Organization. 2020. Food and agriculture data. Rome: Food and Agriculture Organization. http://www.fao.org/faostat/en/\#ho $\underline{\text { me }}$

Food and Agriculture Organization. 2020. FAO Publications Series 2019. FAO Office For Corporate Communication http://www.fao.org/3/ca6126en/ca6 126en.pdf

Geertz, C. 1963. Agricultural Involution: The Process of Ecological Change 
in Indonesia, American

Anthropologist. California:

University of California Press. doi:

10.1525/aa.1968.70.3.02a00550.

Georgas, J., Mylonas, K., Bafiti, T., Poortinga, Y. H., Christakopoulou, S., Kagitcibasi, C., Kwak, K., Ataca, B., Berry, J., Orung, S., Sunar, D., Charalambous, N., Goodwin, R., Wang, W.-Z.,

Angleitner, A., Stepanikova, I., Pick, S., Givaudan, M.,

Zhuravliova-Gionis, I., Konantambigi, R., Gelfand, M. J., Marinova, V., McBride-Chang, C., \& Kodiç, Y. (2001). Functional relationships in the nuclear and extended family: A 16-culture study. International Journal of Psychology, 36(5), 289-300. https://doi.org/10.1080/002075901 43000045

JPPN.com. 2017. FAO: Jumlah Petani Terus Berkurang. https://www.jpnn.com/news/faosayangkan-jumlah-petani-terusberkurang

Korzenszky, A. 2019. Extrafamilial farm succession: an adaptive strategy contributing to the renewal of peasantries in Austria. Canadian Journal of Development Studies, 40(2), pp. 291-308. doi: 10.1080/02255189.2018.1517301.

Kusumo, R. A. B. \& Mukti, G. W. 2019. Potret Petani Muda (Kasus Pada Petani Muda Komoditas

Hortikultura di Kabupaten Bandung Barat). Jurnal Agribisnis, 5(2). doi: 10.30997/jagi.v5i2.2323.

Laa, R. 2018. Pola Asuh Anak dalam Keluarga Petani di Domloli Kabupaten Alor. Al-Asasiyya: Journal Basic of Education, 03(01), pp. 76-104.
Larson, N. C. \& Dearmont, M. 2002. Strengths of Farming Communities in Fostering Resilience in Children.

Leavy, J. \& Smith, S. 2010. Future Farmers: Youth Aspirations, Expectations and Life Choices.

Magagula, B. \& Tsvakirai, C. Z. 2020. Youth perceptions of agriculture: influence of cognitive processes on participation in agripreneurship. Development in Practice. Taylor \& Francis, 30(2), pp. 234-243. doi: 10.1080/09614524.2019.1670138.

Moniaga, A. D., Pauline, W. E., \& B., M. V. R. 2018. Faktor Beralihnya Tenaga Kerja Anak Petani Ke Sektor Non-Pertanian Di Desa Treman Kecamatan Kauditan Kabupaten Minahasa Utara. AgriSosio Ekonomi Unsrat, 14(2), pp. $1-12$.

Mua, V. B., Manginsela, E. P., \& Baroleh, J. 2017. Faktor-Faktor Penyebab Putus Sekolah Dari Anak Petani Dan Non-Petani Di Desa Sea Dan Desa Warembungan Kecamatan Pineleng Kabupaten Minahasa. Agri-SosioEkonomiUnsrat, 13(November), pp. 313-322.

Musrah, E. 2016. Persepsi Keluarga Petani Mengenai Pendidikan Di Desa Lalabata Riaja Kecamatan DonriDonri Kabupaten Soppeng. Jurnal Sosialisasi Pendidikan SosiologiFIS UNM, pp. 1-6.

Nazaruddin and Anwarudin, O. 2020. Pengaruh Penguatan Kelompok Tani Terhadap Partisipasi Dan Motivasi Pemuda Tani Pada Usaha Pertanian Di Leuwiliang, Bogor. Jurnal Agribisnis Terpadu, pp. 114

Nugroho, A. D., Waluyati, L. R., \& Jamhari, J. 2018. Upaya Memikat Generasi Muda Bekerja Pada 
Sektor Pertanian di Daerah Istimewa Yogyakarta. JPPUMA: Jurnal Ilmu Pemerintahan Dan Sosial Politik Universitas Medan Area, 6(1), 76. https://doi.org/10.31289/jppuma.v6 i1.1252

Pamungkaslara, S. B. 2017. Regenerasi Petani Tanaman Pangan di Daerah Perkotaan dan Perdesaan Kabupaten Grobogan. Bumi Indonesia, 6(3).

Pertanian, B. P. \& P. S. D. M. 2015. Rencana Strategis Tahun 20152019. Jakarta: Kementerian Pertanian RI.

Pranadji, T. \& Hardono, G. S. 2015. Mobilitas dan Produktivitas Tenaga Kerja Perdesaan. Panel Petani Nasional: Mobilisasi Sumber Daya Dan Penguatan Kelembagaan Pertanian, 209-221.

Pranata, J. B. 2018 Hubungan Pendidikan Anak dengan Kondisi Petani di Desa Pasirmae Kecamatan Cipeucang Kabupaten Pandeglang. Universitas Pendidikan Indonesia.

Rahayu, Y. 2014. Peran Orang Tua dalam Pendidikan Anak pada Keluarga Petani di Desa Mekar Baru. Jurnal Pendidikan Sosiologi dan Humaniora, 5(2).

Ranzez, M. C., Anwarudin, O., \& Makhmudi, M. 2020. Peranan Orangtua Dalam Mendukung Regenerasi Petani Padi (Oryza Sativa L) Di Desa Srikaton Kecamatan Buay Madang Timur. Jurnal Inovasi Penelitian, 1(2), pp. 117-128.

Rodríguez, L. C., Antonio, J., \& González, C. 2018. How to make prosperous and sustainable family farming in Cuba a reality.
Rusastra, I. W., \& Suryadi, M. (2004). Ekonomi tenaga kerja pertanian dan implikasinya dalam peningkatan produksi dan kesejahteraan buruh tani. Jurnal Litbang Pertanian, 23(3).

Santoso, A. W., Effendy, L., \&

Krisnawati, E. 2020. Percepatan Regenerasi Petani Pada Komunitas Usahatani Sayuran Di Kecamatan Samarang Kabupaten Garut Provinsi Jawa Barat. Jurnal Inovasi Penelitian, 1(3).

Scott, J. C. 1976. The Moral Economy of the Peasant: Rebellion and Subsistence in Southeast Asia. New Haven: Yale University Press.

Suryati, D. \& Yuniati, M. 2017. Analisis Pemanfaatan Sumber Daya Anak Dalam Keluarga Untuk Mencapai Kesejahteraan Islami Pada Rumah Tangga Petani Di Kecamatan Sape Kabupaten Bima. GaneC Swara, 11(2), pp. 111-117.

Susilowati, S. H. 2016. Fenomena Penuaan Petani dan Berkurangnya Tenaga Kerja Muda Serta Implikasinya Bagi Kebijakan Pembangunan Pertanian. Forum Penelitian Agro Ekonomi, 34(1), pp. 35-55.

The European Access to Land Network. 2018. Europe's new farmers: Innovative ways to enter farming and access land.

Zapico, F., Hernandez, J., Borromeo, T., Mcnally, K., Dizon, J., Baños, L., \& Fernando, E. 2019. Traditional agro-ecosystems in the Southern Philippines: Vulnerabilities, threats and interventions. 10(4), 289-300. https://doi.org/10.1108/IJDRBE06-2019-0036 